\title{
INTRODUÇÃO
}

\section{RELIGIÃO NA GRÉCIA E ROMA ANTIGAS: CONTATOS, ENCONTROS E TROCAS ${ }^{1}$}

A natureza fragmentária e variada do Mediterrâneo foi estudada por pesquisadores que se dedicaram, de fato, a entender a região. As ideias revolucionárias da obra pioneira de Fernand Braudel, La Méditerranée et le Monde méditerranéen à l'époque de Philippe II (1949), mudaram o foco do espaço mediterrânico, deslocando-o de suas fronteiras continentais para a bacia marítima, bem como reorientaram a pesquisa histórica da região, encaminhando-a da política para a cultura e a economia. É certo que, depois de Braudel, foram necessários muitos anos para que os estudos na escala mediterrânica se tornassem tendência. A nova contribuição significativa foi feita por Peregrine Horden e Nicholas Purcell, com a publicação The Corrupting Sea: A Study of Mediterranean History (2000), que identificou elementos comuns ao longo dos mais de três mil anos de história no Mediterrâneo. Explorando a extrema fragmentação da região em suas paisagens terrestres e marinhas, os autores produziram uma análise inovadora das relações entre suas diferentes microecologias. Horden e Purcell evidenciaram o peso do elemento da incerteza nos microcosmos mediterrânicos, seja quanto ao clima e à quantidade de precipitação, seja quanto à direção e a intensidade do vento, e ainda quanto à possibilidade de catástrofes vulcânicas e sísmicas. Por outro lado, se o Mediterrâneo passa então a ser pensado enquanto uma área de incerteza, entende-se que ele se constituiu também como região de grande mobilidade, dados seu elevado número de ilhas e a extensão de sua área costeira, a maior do planeta. Com efeito, o fato de seus navegadores raramente perderem de vista a terra e do sol

1 Nós gostaríamos de agradecer o convite para organizarmos este dossiê e toda a assistência durante a confecção do número à Renatta Garraffoni (UFPR) e Priscila Vieira (UFPR), agora à frente da editoria da Revista História: Questões \& Debates. Somos também enormemente gratas a Yannos Kourayos, que cedeu os direitos de uso da foto de capa, com o recém-restaurado edifício A do santuário de Despótiko. Estendemos nosso agradecimento ainda a Andrew Gipe Lazarou (Diakron Institute) que produziu a capa e fez a revisão do texto em inglês desta introdução. Qualquer erro que persista é, no entanto, de nossa inteira responsabilidade. 
brilhar durante todo o ano fez do Mediterrâneo um espaço de oportunidades, o que encorajou os homens a diversificarem, produzirem e explorarem.

Esse poder que o Mediterrâneo tem de conectar mundos é explorado num outro livro monumental do século XXI, The Making of the Middle Sea (2014). Seu autor, Cyprian Broodbank, utiliza uma vasta quantidade de dados arqueológicos para desvelar a história da região, de um milhão e oitocentos mil anos atrás até o Período Clássico, demonstrando como o mundo mediterrânico, facilmente navegável e ecologicamente fragmentado, evoluiu para uma oecumene através da agência dos habitantes de suas ilhas e costas.

A natureza fragmentária da região mediterrânica é, com efeito, uma de suas características mais distintivas. Ela atua como estímulo histórico para a formação de redes de transporte complexas, responsáveis por ligarem lugares de tamanhos e importância desiguais, da família aos estados imperiais, e por envolverem todo tipo de atores, do comerciante ao monarca (MALKIN; CONSTANTAKOPOULOU; PANAGOPOULOU, 2011). O Mediterrâneo, por isso, permitiu o movimento de multidões em torno da sua vasta área, não só devido à proximidade dos seus locais costeiros e suas ilhas, mas também devido às condições climáticas (ou seja, um verão semi-árido e um inverno úmido) amplamente favoráveis à disseminação de produtos e técnicas (agricultura, perfumaria, cerâmica, navegação) (BROODBANK, 2014). A extensa circulação de pessoas e bens no Mediterrâneo reflete-se também na natureza das práticas religiosas da região. Objetos provenientes de todo o mundo antigo eram apresentados como ofertas em túmulos e santuários pela região mediterrânica. As práticas religiosas, por sua vez, eram transmitidas durante diferentes ciclos de convulsões sociais e migrações, o que envolvia o contato tanto de habitantes de áreas próximas entre si quanto daquelas situadas a grandes distâncias, cuja comunicação se dava por meio da rede de rotas.

Este dossiê apresenta então estudos de caso que enfatizam a diversidade cultural e os intercâmbios religiosos no mundo greco-romano, centrando-se nas relações entre fragmentos da região mediterrânica (MALKIN, 2011). Com nove artigos em múltiplas áreas temáticas, os primeiros cinco se desenvolvem no campo da Arqueologia Clássica, e os quatro seguintes em História e Literatura. As contribuições (feitas em português, inglês e francês) provêm de pesquisadores que trabalham sobre diferentes aspectos da religião no mundo greco-romano. Iniciamos com uma investigação sobre trocas e práticas de culto no coração das Cíclades, onde se deu uma das mais importantes descobertas arqueológicas realizadas na 
Grécia nos últimos dez anos. Yannos Kourayos e Kornilia Daifa, que dirigem as escavações em Despótiko, apresentam em seu texto um panorama deste que é um importante santuário cicládico, só conhecido a partir de evidências arqueológicas. Localizado no centro da região cicládica, o santuário em questão foi erigido pela poderosa ilha de Paros e revelou uma quantidade impressionante de oferendas votivas originárias de múltiplos pontos das Cíclades e também de partes mais afastadas do Mediterrâneo. O segundo trabalho deste volume, escrito por Elena Korka e membros de sua equipe, divulga alguns dos recentes resultados das escavações em Tenea, situada nos arredores da aldeia de Chiliomodi em Corinto, um local cuja cultura material e ciclo de mitos estão ligados à Guerra de Tróia. Depois de sumarizar o trabalho arqueológico realizado até agora, os autores discutem a principal divindade adorada em Tenea, o deus Apolo, e os artefatos encontrados ali, importantes para a interpretação e o entendimento do antigo culto. Vale destacar que alguns dos objetos escavados têm suas imagens publicadas pela primeira vez neste dossiê. O próximo artigo, escrito por Michael Fowler da East Tennessee State University, examina os quatro monumentos tumulares arcaicos tardios da Necrópole Setentrional do povoado grego de Istros. O autor explora as características desses monumentos comparáveis à descrição das cerimônias heroicas de cremação, tal como narradas na poesia épica (particularmente, no caso do funeral de Pátroclo na Ilíada) e discute, ainda, a possibilidade surpreendente de sacrifício humano. Para além dos hábitos religiosos incomuns entre os gregos e das reconsiderações sobre a Pira A em Orthi Petra (Eleutherna, Creta), a discussão de Fowler inclui também em seu estudo um sítio arqueológico situado no Mar Negro, região que segue pouco estudada fora dos círculos acadêmicos russos. Do Mar Negro, nosso dossiê retorna para Corinto, desta vez às margens do golfo. Dora Katsonopoulou, diretora das escavações em Helike, discute o culto de Poseidon Helikonios com ênfase nos antigos altares ancestrais dos jônicos. Ela examina o estabelecimento do culto de Poseidon Helikonios, trazido pelos aqueus para a costa da Ásia Menor, transmitido em seguida para a já mencionada região do Mar Negro. O próximo trabalho, escrito por Lilian Laky da Universidade de São Paulo, explora a interconectividade do Mediterrâneo examinando a iconografia das moedas com imagens de águias e relâmpagos, atributos de Zeus. A autora utiliza como fontes moedas cunhadas por Crótone na Magna Grécia e por Olympia no Peloponeso para discutir a difusão do culto de Zeus Olympios. Contribuindo para o tema da relação entre Olympia e 
Sicília, o artigo, ademais, dá um importante aporte para os estudos sobre a disseminação regional dos epítetos locais, tema pouco abordado que, porém, está lentamente ganhando a atenção necessária.

Os próximos quatro textos de nosso dossiê examinam os contatos e as trocas entre as religiões gregas e romanas pelas lentes da História e da Literatura antiga. Esta seção é aberta com um artigo de Pierre Ellinger, da Université de Paris. O autor analisa os raptos de estátuas divinas de santuários à beira-mar, a partir de mitos gregos, especialmente o de Ártemis Táurida, tal como elaborado pela tragédia euripideana, enfatizando-o. $\mathrm{O}$ texto explora a presença do mar nesses registros antigos, dando destaque às rotas mediterrânicas e sua articulação com determinados pontos, à experiência de partida e de chegada e ao contexto em que tais estórias teriam sido narradas. Ao ressaltar a dimensão marítima dessas fontes, o autor põe em questão a nossa familiaridade com o espaço grego, reorientando nossa perspectiva da visão da cidade para a visão do mar ao longo de suas margens. O artigo, portanto, não só lança luz sobre o culto enigmático de Ártemis Táurida, cujo culto continua a confundir e intrigar os estudiosos modernos, como apresenta uma grande contribuição para os estudos emergentes sobre as religiões mediterrânicas.

Em seguida, o texto de autoria de Lucio Maria Valletta da École Pratique des Hautes Études, discute novos cultos da região do Mar Negro. $\mathrm{O}$ autor examina uma passagem de Heródoto sobre o povo cita para refletir sobre a existência de elementos culturais que seriam próprios a povos que viveram e se deslocaram nas regiões circundantes da bacia do Mediterrâneo, incluindo o Mar Negro. O dossiê segue com o trabalho de Júlia Avelar, da Universidade Federal de Uberlândia, que aborda cultos romanos e festivais religiosos do início do Império por meio do trabalho do poeta romano Ovídio. Avellar examina as intersecções entre cultos privados e festivais públicos na Roma antiga. A autora demonstra de que forma os cultos religiosos da poesia ovidiana seriam recriações poéticas que, através de elementos religiosos, provocam reflexões sobre as relações de poder na Antiguidade. Voltando às Cíclades e a Paros, o último trabalho deste volume, escrito por Rafael Silva e Teodoro Rennó Assunção da Universidade Federal de Minas Gerais, parte de fragmentos ditirâmbicos atribuídos a Arquíloco (fr. 120 W, fr. 96 Lasserre) para desenvolver considerações sobre a relação entre o culto de Dioniso e a difusão do ditirambo. 
Juntos, os artigos apresentados neste volume expõem a riqueza das trocas religiosas no Mediterrâneo, particularmente no mundo greco-romano. Enquanto alguns revelam pesquisas arqueológicas originais sobre regiões sócio-políticas estratégicas, outros apresentam autênticos quadros teóricos, capazes de iluminar a complexidade dos intercâmbios culturais observados pela disseminação tanto da cunhagem oficial quanto dos mitos vernáculos.

Erica Angliker (Institute of Classical Studies, University of London). Lorena Lopes da Costa (Universidade Federal do Oeste do Pará).

Esta edição da História Questões \& Debates ainda conta com contribuições de três artigos que compõem a sessão livre da Revista. Em "Movimentos de luta pela terra no norte do RS: o acampamento Capão da Cascavel na Fazenda Sarandi (1960/62)", João Carlos Tedesco e Joel João Carini analisam o contexto de desenvolvimento das ações do Movimento dos Agricultores Sem Terra no norte do Rio Grande do Sul, centralizando sua análise no acampamento Capão da Cascavel. Já Alfredo Ricardo Silva Lopes, em "Memórias Coletivas, Traumas Individuais: as memórias dos desastres socioambientais no sul de Santa Catarina (1974-2004)", dá destaque para as memórias coletivas produzidas pelos entrevistados sobre desastres socioambientais, que ocorreram no sul de Santa Catarina, entre 1974 e 2004. O último artigo, "Cidade, natureza e urbanização: proposições para uma história ambiental da Região Metropolitana de Porto Alegre/RS", é escrito por Danielle Heberle Viegas, Eduardo Relly e Cleusa Maria Gomes Graebin e tem como proposta pensar a história de cidades da Região Metropolitana de Porto Alegre por meio das ferramentas analíticas e conceituais da história ambiental, utilizando como material de pesquisa fotografias, cartografia, documentação administrativa e expressões das memórias dos moradores. Agradecemos a contribuição das autoras e dos autores e desejamos a todos uma excelente leitura! 